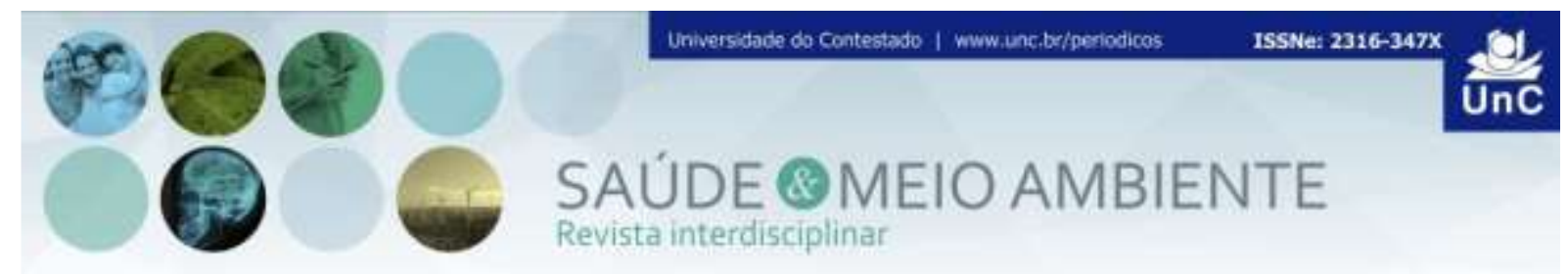

\title{
PRINCÍPIO DA INTEGRALIDADE E AS REDES DE ATENÇÃO À SAÚDE EM MICRO TERRITÓRIO CATARINENSE
}

\section{PRINCIPLE OF INTEGRALITY AND HEALTH CARE NETWORKS IN MICRO TERRITORY CATARINENSE}

\author{
Maria Luiza Milani ${ }^{1}$ \\ Daniele Ennes Brey² \\ Esvaldo Antunes ${ }^{3}$
}

\begin{abstract}
RESUMO
A reflexão deste estudo trata da política pública de saúde brasileira pelas intervenções de forma regionalizada e promoção da saúde, tendo como princípio a integralidade, por meio de composição de redes de atenção à saúde, em microterritório catarinense. Justifica-se os conhecimentos apresentados diante do intenso processo de consolidação do SUS, ao se destacar o estágio que o processo da regionalização e das redes avançou diante das diretrizes e intervenções na regional de saúde de Mafra. O objetivo abordou aspectos referentes à questão da regionalização e nela as redes, com análise acerca do que se pôde perceber sobre os contratempos e avanços na regional de saúde de Mafra, no qual se vivenciou um processo de organização e implementação de redes em saúde intra e inter território, uma vez que a política de gestão do governo catarinense se anunciava regionalizado e preocupado com o fortalecimento das estruturas locais e regional, nas várias frentes preconizadas pelas políticas públicas não apenas na saúde. 0 Estado deveria ser o coordenador desse processo, porém, no microterritório da regional de saúde de Mafra os desencontros, as mudanças de gestão e de gestores atrasaram esse processo. Conclui-se que falta de empenho na disseminação do conhecimento como compromisso moral do governo brasileiro pela saúde pública, assegurado constitucionalmente, se perde pela incompreensão desta sua atribuição e o acúmulo de experiências que subsidiaram a caminhada na implantação da saúde pública, na implementação das redes de atenção, que se perdem com essas mudanças.
\end{abstract}

Palavras-chave: Redes de atenção à saúde. Integralidade. Promoção da saúde. SUS.

\footnotetext{
${ }^{1}$ Doutora em Serviço Social, docente do Programa de Mestrado em Desenvolvimento Regional. Universidade do Contestado. Santa Catarina. Brasil. E-mail: marialuiza@unc.br

${ }^{2}$ Assistente social. Secretaria de Estado de Saúde de Santa Catarina. Santa Catarina. Brasil. E-mail: daennes@gmail.com

${ }^{3}$ Enfermeiro, Mestre em Desenvolvimento Regional, Universidade do Contestado. Santa Catarina. Brasil. E-mail: evlantune@hotmail.com
} 


\begin{abstract}
The reflection of this study deals with the Brazilian public health policy by interventions in a regionalized way and health promotion, having as its principle integrality, through the composition of health care networks, in microterritory in Santa Catarina. It is justified the knowledge presented in the face of the intense process of consolidation of the SUS, highlighting the stage that the process of regionalization and networks advanced in the face of guidelines and interventions in the regional health of Mafra. The objective addressed aspects related to the issue of regionalization and in it the networks, with analysis about what could be perceived about the setbacks and advances in the regional health of Mafra, in which a process of organization and implementation of networks was experienced in intra- and interterritory health, since the management policy of the Government of Santa Catarina was regionalized and concerned about the strengthening of local and regional structures, on the various fronts recommended by public policies not just in health. The State should be the coordinator of this process, however, in the microterritory the disagreements, the changes in management and managers delayed this process. It is concluded that a lack of commitment to the dissemination of knowledge as a moral commitment of the Brazilian government for public health, constitutionally assured, is lost by the misunderstanding of this attribution and the accumulation of experiences that supported the public health implementation, in the implementation of care networks, which are lost with these changes.
\end{abstract}

Keywords: Health care networks. Integrality. Health promotion. SUS.

\title{
INTRODUÇÃO
}

Ao longo dos últimos 80 anos a saúde pública no Brasil é tema recorrente na pauta política tanto na sua concepção, organização, preservação e por fim, quanto aos recentes enfrentamentos que dizem respeito às ameaças que pairam sobre o Sistema Único de Saúde (SUS), em particular a partir do ano de 2016.

O processo que se instaura no Brasil no final do século XX (BRASIL, 2006) é o reconhecimento assegurado e legitimado pela Constituição da República Federativa do Brasil, (CRFB) de 1988 e pela Lei Orgânica de Saúde (LOS), em 1990, de uma saúde pública, não contributiva, universalizada e de atendimento integral. Porém, o longo caminho da universalização e o atendimento integral esbarram na processual, complexa e restrita implementação do sistema que significa a consolidação do SUS.

A saúde pública brasileira pós 1988 se constitui pela transformação do modelo de atendimento prestado pelo Estado brasileiro (estrutura seletiva, contributiva e com grau preocupante de efetividade), para uma política de direito universal de responsabilidade do Estado, imbuída da responsabilidade em cumprir o disposto constitucional, tendo por base a concepção de saúde ampliada, lançada durante a $8^{\text {a }}$ Conferência Nacional de Saúde em 1986. 
A concepção ampliada de saúde apresentada por Arouca em 1986, por si só implica no fortalecimento de um dos princípios do SUS: integralidade, como também direciona para estratégias de operacionalidade com organização intersetorial, intra e inter intervenções.

Nessa direção, o texto aborda as potencialidades e as possibilidades que permeiam as políticas públicas de saúde na sustentação de redes de atenção à saúde como estratégia central para a integralidade.

$\mathrm{Na}$ perspectiva de retratar um processo instaurado em microterritório catarinense, abrangido pela gerência regional de saúde (Mafra) no Estado catarinense, no qual se vivenciou processo de organização e implementação de redes em saúde intra e inter território, uma vez que a política de gestão do governo catarinense se anunciava regionalizado e preocupado com o fortalecimento das estruturas locais e regional, nas várias frentes preconizadas pelas políticas públicas não apenas na saúde.

As determinações acerca do escopo do tema, (regionalização, redes e promoção da saúde) e os limites que o processo concreto, mesmo com intenso investimento alcançou até a reorganização das regionais de saúde de Canoinhas e Mafra, unificadas apenas como a de Mafra, são decorrentes da decisão política do governo catarinense em extinguir estruturas regionais do governo estadual.

Nas décadas posteriores a 1988, profissionais, gestores, movimentos sociais, serviços e a população brasileira, têm perseguido a consolidação do SUS por meio da execução de distintas frentes e estratégias e diversas metodologias para nortear a implementação das ações em saúde, conforme prevê a CFB (de 1988), Título VII da ordem social, capítulo I - disposição geral, seção II (artigos 196 a 200) os quais estabelecem os parâmetros que devem respaldar estas transformações no campo da saúde.

A política pública social de saúde deve perseguir o conceito ampliado de saúde proposto e aprovado na $8^{a}$ Conferência Nacional de Saúde, realizada no Brasil de 17 a 21 de março de 1986. Sob esta orientação, a promoção em saúde e prevenção de agravos, demandam ações intersetoriais, que extrapolem a responsabilidade exclusiva do setor saúde.

O SUS brasileiro deveria ser composto por uma organicidade de estruturas, serviços e profissionais para atender as suas atribuições preconizadas pela CRFB de 1988 de se promover a saúde integral, priorizando as ações preventivas e democratizando as informações relevantes para que a população conheça seus direitos e os riscos à sua saúde.

Ao final dos anos de 2010, a discussão se encaminha para a agilização e organização de redes de atenção à saúde (MENDES, 2011), considerando a fragmentação da atenção à saúde, fatores demográficos, agravamentos de doenças crônicas, sustentavam a organização e implementação de redes.

Entre os desafios desencadeados para concretizar a concepção de saúde, há os que se voltam tanto para a promoção em saúde como para a prevenção de 
agravos, ambos processos respaldados no disposto constitucional (CRFB de 1988) no artigo Art. 198 que prevê "As ações e os serviços públicos de saúde integram uma rede regionalizada e hierarquizada e constituem um sistema único organizado de acordo com as diretrizes de descentralização, regionalização, atendimento integral e participação da comunidade". Por conseguinte, a Lei 8080 de 1990, estabelece em seu artigo $7^{\circ}$, inciso II a "[...] integralidade de assistência, entendida pelo conjunto articulado e contínuo das ações e serviços preventivos e curativos, individuais e coletivos [...]". Complementado pelo o artigo 10 o qual "[...] aponta arranjos organizacionais para as redes loco-regionais através de consórcios intermunicipais e distritos de saúde como forma de integrar e articular recursos e aumentar a cobertura das ações" (BRASIL, 1988). Logo, a relação integralidade na saúde converge com a composição de redes de atenção à saúde.

Sob esses aspectos, este artigo expõe a conjugação de esforços na regional de saúde de Mafra, encampados inicialmente pelas Regionais de Saúde de Canoinhas e Mafra até elas serem integradas em uma só, para que se avançasse na operacionalização da saúde pública, composição de redes de atenção à saúde nesse território, processo iniciado no ano de 2009, concomitante às publicações e orientações nessa direção. Ou seja, até que estágio o processo se avançou diante das diretrizes e intervenções conduzidas na regional de saúde de Mafra?

Portanto, se aborda aspectos referentes à questão da regionalização e nela as redes que conseguiram ser discutidas, com análise acerca do que se pôde perceber da relação entre esses temas a partir do estágio que se atingiu na regional de saúde de Mafra.

A experiência apresentada e sob ela tecidas reflexões, tem como objetivo apontar questões de ordem intra e inter saúde pública que possam ter interferido na implementação das redes de atenção à saúde no território.

\section{METODOLOGIA}

O texto apresentado é resultado de pesquisa participante (THIOLLENT, 1999), que oportunizou o recolhimento e descrição de conhecimentos in loco, no período e nos lugares em que os processos iam acontecendo, pelas práticas dos governos e profissionais, envolvimento de entes institucionais governamentais e não governamentais. Os procedimentos operativos da pesquisa foram norteados pela abordagem qualitativa (MINAYO, 2009). A coleta de dados ocorreu pelos procedimentos bibliográfico e documental (GIL, 2002), de caráter exploratório (GIL, 2002), cujos resultados foram sistematizados e analisados seguindo o procedimento da análise de conteúdo (GIL, 2002). 


\title{
REGIONALIZAÇÃO E REDES NA SAÚDE PÚBLICA
}

A concepção de saúde expressa por Arouca em 1986, assegura o direito a ter direito a proteção social integral, diante da gravidade do estado de saúde da população. Essa concepção de saúde respalda este estudo e para a qual

[...] saúde não é simplesmente ausência de doença: é um bem-estar físico, social, afetivo e que pode significar que as pessoas tenham mais alguma coisa do que simplesmente não estar doentes: que tenham direito à casa, ao trabalho, ao salário condigno, à água, à vestimenta, à educação, às informações sobre como dominar o mundo e transformá-lo. Que tenham direito ao meio ambiente que não os seja agressivo, e que, pelo contrário, permita uma vida digna e decente. Direito a um sistema político que respeite a livre opinião, a livre possibilidade de organização e autodeterminação de um povo, e que não esteja todo tempo submetido ao medo da violência, daquela violência resultante da miséria, e que resulta no roubo, no ataque. Que não esteja também submetido ao medo da violência de um governo contra o seu próprio povo, para que sejam mantidos interesses que não são do povo [...] (AROUCA, 1986).

As concepções apresentadas são fundamentadas nas diretrizes que imprimem à política pública de saúde, bases para consolidar o sistema de saúde conforme a CRFB de 1988, Art. 198,

\begin{abstract}
As ações e serviços públicos de saúde integram uma rede regionalizada e hierarquizada e constituem um sistema único, organizado de acordo com as seguintes diretrizes: I - Descentralização, com direção única em cada esfera de governo; II - Atendimento integral, com prioridade para as atividades preventivas, sem prejuízo dos serviços assistenciais; III - participação da comunidade (BRASIL, 1988)
\end{abstract}

Isto é, preconiza um Sistema Único de Saúde (SUS), referência para a América Latina, a operacionalização de um sistema regionalizado e hierarquizado e em conexão. Conforme Milani e Vandresen (2019, p. 480) nessa conexão "há que se considerar um processo complexo constituído de determinações que representam interesses de atores sociais locais, regionais e internacionais".

Isso posto, os interesses dos atores devem fazer referência ao bem-estar e à qualidade de vida de um povo. Nesta direção, a integralidade de atenção à saúde não deve ser deslocada da universalidade. Os dois princípios requerem medidas estratégicas ampliadas.

Ainda conforme as autoras Milani e Vandresen (2019, p. 480) as estratégias devem convergir com os interesses que "buscam responder ao disposto constitucional" (BRASIL, 1988), da integralidade, universalidade e gratuidade, para o que as diretrizes internacionais contribuem com os processos brasileiros no escopo local e regional", mas que se operados no circuito de uma região, a propagação das intervenções instaurará resolutividade continuada. 
A diretriz da regionalização da saúde toma como referência a demarcação social e geográfica, na qual coexistem múltiplas dimensões da vida humana, entre elas a socioeconômica e nesta dimensão, a saúde.

Posto desta forma, a marcação da região em saúde pública brasileira, referese aos limites geográficos e sua população (MS, SAS, 2014), com um rol de "ações e serviços que a região irá garantir à população e as responsabilidades dos entes federativos com a sua execução e financiamento, além dos critérios de acessibilidade e a escala na conformação dos serviços" (SANTOS, 2017, p. 1283).

Na delimitação da região, o bem-estar populacional deve ser relacionado com as melhorias políticas, econômicas, culturais e humanas, que podem ocorrer de forma singular em cada região, dependendo de ações que favoreçam a qualidade de vida das pessoas.

O processo de regionalização no Brasil necessitou de vários fatores que são compartilhados pelas três esferas de gestão, assim como aspectos que são inerentes à questão socioeconômica e política de cada região. Entre os fatores, o âmbito da organização governamental estadual desempenha papel essencial de agente organizador, mediador e modulador, responsável pela condução e coordenação direta das ações junto aos municípios que compõem as regiões.

Esse sistema hierarquizado e regionalizado deve favorecer a constituição das Redes de Atenção à Saúde (RAS). Estas são arranjos organizativos de ações e serviços de saúde de diferentes densidades tecnológicas, que integradas por meio de sistemas de apoio técnico, logístico e de gestão, que buscam garantir a integralidade do cuidado, conforme a Portaria $\mathrm{n}^{\circ} .4 .279$ de 2010 (BRASIL, 2010).

"O objetivo precípuo da RAS é prestar atenção integral, de qualidade e resolutiva, que atenda às reais necessidades da população, tendo em vista a atual situação epidemiológica e demográfica do País, que vem se dando de forma acelerada, com predominância das condições crônicas" (CONASS, 2015, p. 9).

Com base nas orientações legais da política pública de saúde brasileira, é possível evidenciar no cenário cotidiano, situações e questões que seguram a operacionalidade do SUS e por conseguinte a constituição das redes de atenção à saúde. Antes, se faz necessário retomar a legitimação do direito constitucional universal à saúde aos brasileiros, para ser agilizar a concepção de rede com centralidade na promoção da saúde.

Conforme a Norma Operacional de Assistência à Saúde (NOAS) SUS 01, (Portaria GM/MS n 95, de 26 de janeiro de 2001), a promoção da saúde com "maior equidade na alocação de recursos e no acesso da população às ações de saúde em todos os níveis de atenção", depende de estratégias inovadoras para o seu desenvolvimento.

Entre as direções referendadas pelo Ministério da Saúde, a Portaria GM/MS $n^{0} 2.669$ (03 de novembro de 2009), estabelece o "Pacto pela Vida, organizado em onze metas prioritárias e respalda a constituição de campos estratégicos para [...] VPromoção da saúde e o VI- Fortalecimento da atenção básica; [...]". 
Estas metas aportam políticas públicas de saúde, pelas quais as atribuições e ações em campos estratégicos da saúde da população envolvem a atenção primária para a prevenção e a promoção da saúde.

Convergente a essa política, o Plano Nacional de Saúde (PNS), lançado em 2011 (vigência 2012-2015), define o foco na promoção do acesso com qualidade às ações e serviços de saúde para o fortalecimento do SUS, mesmo que desde 2006 a promoção de saúde tivesse se tornado base de uma política especial: a Política Nacional de Promoção da Saúde estabelecida pela Portaria MS/GM 687 (30 de março de 2006).

Para enfrentar essas questões, o PNS aponta as diretrizes e metas a serem alcançadas, tendo como objetivo o aprimoramento do SUS, visando o acesso universal, de qualidade, em tempo oportuno, contribuindo para a melhoria das condições de saúde, para a redução das iniquidades e para a promoção da qualidade de vida dos brasileiros.

Nesse contexto o PNS (2012-2015) estabelecia três importantes diretrizes vinculados à concepção de rede. A Diretriz 1 que define a organização e aprimoramento da atenção básica e da atenção especializada. (BRASIL, PNS, 2011), indica que essa atenção deve se compor de recursos, serviços e estruturas, para que esta processe a atenção primária; se constituam redes conforme define a Portaria 4.279 (30.12.2010, do MS, 2010), que observem os princípios da universalidade, acessibilidade, vínculos, continuidade do cuidado. Portanto, as unidades básicas de saúde, instaladas em territórios deveriam favorecer o acesso e o atendimento dos usuários. Essas orientações são corroboradas pelo decreto 7.508 de 28 de junho de 2011, o qual regulamenta a lei 8080 de 1990 (Lei Orgânica da Saúde-LOS). Esse decreto no seu Art. $2^{\circ}$, diz que

\footnotetext{
Considera-se: I - Região de Saúde - espaço geográfico contínuo constituído por agrupamentos de Municípios limítrofes, delimitado a partir de identidades culturais, econômicas e sociais e de redes de comunicação e infraestrutura de transportes compartilhados, com a finalidade de integrar a organização, o planejamento e a execução de ações e serviços de saúde; II - Contrato Organizativo da Ação Pública da Saúde - acordo de colaboração firmado entre entes federativos com a finalidade de organizar e integrar as ações e serviços de saúde na rede regionalizada e hierarquizada, com definição de responsabilidades, indicadores e metas de saúde, critérios de avaliação de desempenho, recursos financeiros que serão disponibilizados, forma de controle e fiscalização de sua execução e demais elementos necessários à implementação integrada das ações e serviços de saúde; [...].; V - Mapa da Saúde - descrição geográfica da distribuição de recursos humanos e de ações e serviços de saúde ofertados pelo SUS e pela iniciativa privada, considerando-se a capacidade instalada existente, os investimentos e o desempenho aferido a partir dos indicadores de saúde do sistema; VI - Rede de Atenção à Saúde - conjunto de ações e serviços de saúde articulados em níveis de complexidade crescente, com a finalidade de garantir a integralidade da assistência à saúde.
}

Do mesmo modo, a Diretriz 2, define a conjugação das estruturas e serviços para as redes de Urgência e Emergência, composta por: Rede de Atenção às Urgências, Unidades de Pronto Atendimento (UPA), Serviços de Atendimento Móvel 
de Urgência (SAMU) e de prontos-socorros e centrais de regulação. Estas articuladas às outras redes de atenção.

A Diretriz 7, relacionada aos riscos e agravos à saúde da população, que requerem a promoção e vigilância em saúde, poderia ser consolidadas pelas diferentes redes possíveis e em recortes regionais, cujas principais proximidades com a população podem ocorrer pela atenção primária e de urgência e emergência. No entanto, para tornarem-se eficazes, quanto mais princípios da regionalização puderem ser efetivados, tanto mais equidade, integralidade, se alcançará pelas intervenções em saúde, decorrentes da promoção em saúde e prevenção de agravos.

Exposto o contexto da regionalização do atendimento à população pela saúde pública, os recursos estratégicos que vêm sendo indicados é a organização e a operacionalização da atenção à saúde em forma de rede.

Mendes (2011, parafraseando Fleury E Ouverney, 2007), aponta que as redes têm sido propostas para administrar políticas e projetos em que os recursos são escassos e os problemas complexos; como há interação de agentes públicos e privados, centrais e locais, em que se manifestam em crescente demanda por benefícios, como também por participação cidadã.

Para a Organização Mundial da Saúde (OMS) uma rede de atenção à saúde deve contemplar seis modalidades de integração: um conjunto amplo de intervenções preventivas e curativas para uma população; os espaços de integração de vários serviços; a atenção à saúde contínua, ao longo do tempo; a integração vertical de diferentes níveis de atenção; a vinculação entre a formulação da política de saúde e a gestão; e o trabalho intersetorial (MENDES, 2011 apud OMS).

A proposição da concepção e operacionalização de redes no Brasil teve aporte em duas diretrizes internacionais: a emitida pela OMS (2008), a qual indica uma base para a definição de redes, seria a oferta de serviços integrados de saúde, como " gestão e a oferta de serviços de saúde de forma a que as pessoas recebam um contínuo de serviços preventivos e curativos, de acordo com as suas necessidades, ao longo do tempo e por meio de diferentes níveis de atenção à saúde"; a Organização Pan-Americana da Saúde (OPAS) indica que para as redes integradas de serviços de saúde, dois requisitos são importantes: a população e território.

A indicação desses dois requisitos (população e território), converge com preceitos contemplados nas diretrizes da regionalização de saúde, referentes às intervenções necessárias aos interesses populacionais mais próximos ao SUS e instala uma direção de proximidade e articulação dos arranjos organizados para as intervenções em saúde, que garantam a integralidade do cuidado.

Os aspectos considerados para fundamentar a concepção e operacionalidade das redes de atenção à saúde permitem ser sintetizados e agregam atributos e temáticas, que segundo Mendes $(2011,82)$, pode-se definir como sendo 
[...[ organizações poliárquicas de conjuntos de serviços de saúde, vinculados entre si por uma missão única, por objetivos comuns e por uma ação cooperativa e interdependente, que permitem ofertar uma atenção contínua e integral a determinada população, coordenada pela atenção primária à saúde - prestada no tempo certo, no lugar certo, com o custo certo, com a qualidade certa, de forma humanizada e com equidade - e com responsabilidades sanitária e econômica e gerando valor para a população.

As deliberações do Ministério da Saúde no direcionamento da operacionalização do SUS, pela organização das Redes de Atenção à Saúde, constituem uma sequência de documentos que orientam e legalizam as intervenções em forma de redes. De acordo com o documento Redes de Atenção à Saúde: a atenção à saúde organizada em rede de Nerícia Regina de Carvalho Oliveira (UNA SUS, UFMA, 2016, p. 11-12), as redes que deveriam ser implementadas a partir da Portaria $n^{\circ}$ 4.279/2010, seriam: Rede Cegonha-Portaria $n^{\circ}$ 1.459/2011; Rede de Urgência e Emergência (RUE)-Portaria GM/MS no 1.600/2011; Rede de Atenção Psicossocial (RAPS)-Portaria GM/MS n 3.088/2011; Rede de Cuidados à Pessoa com Deficiências (Viver Sem Limites)-Portaria GM/MS n 793/2012; Rede de Atenção à Saúde das Pessoas com Doenças Crônicas- Portaria GM/MS n ${ }^{\circ}$ 438/2014.

Diante da complexa e diversificada situação ambiental e territorial, por conseguinte da situação de saúde populacional no território nacional, as RAS emergem e são respaldadas como uma possibilidade de correção dos desafios que o cenário da saúde pública e das questões anunciavam, consistindo-se [...] em arranjos organizativos de ações e serviços de saúde, de diferentes densidades tecnológicas, que integradas por meio de sistemas de apoio técnico, logístico e de gestão buscam garantir a integralidade do cuidado (CONASS, 2015).

Por conseguinte, o Plano Nacional de Saúde (PNS, vigência 2016-2019) situa o compromisso dos entes governamentais de suas responsabilidades constitucionalmente definidas, para que o SUS seja contemplado por uma infraestrutura de oferta com estabelecimentos da rede pública, abrangendo unidades privadas atuantes no mercado. Para o enfrentamento desses desafios, faz-se necessário continuar ampliando o acesso da população às ações e serviços de saúde de forma integral, mais humana, oportuna, com qualidade e equidade, segundo as necessidades individuais e coletivas.

Ainda, o PNS (2016-2019) destaca que as redes de atenção como organizações devem produzir intervenções e serviços de saúde na perspectiva do cuidado. Este cuidado deve manter seu escopo nas necessidades em saúde, (tendo em vista a complexa peculiaridade dos ciclos de vida-criança, adolescente, jovem, adulto e idoso), como também, as especificidades de gênero, geográfica, econômica, social e étnica, que na medida do avanço das políticas públicas se tornaram recortes de atenção.

Um sistema com o compromisso do atendimento e respostas de forma integral, deve promover uma ampla articulação para o reordenamento e execução do trabalho em saúde. A implementação e implantação de uma rede de serviços de saúde, aprimora as atribuições da promoção em saúde e prevenção de agravos, 
com cuidado contínuo e em consonância com os compromissos preconizados constitucionalmente, do processo acerca das redes de atenção à saúde na região denominada Planalto Norte Catarinense, apoiada institucionalmente pela Associação dos Municípios (AMPLANORTE).

\section{RESULTADOS}

Os resultados da pesquisa participante são obtidos pela observação dos fatos na temporalidade entre 2015 a 2017 (ainda quando as regionais de saúde de Canoinhas e Mafra eram separadas), em uma primeira etapa e em uma segunda etapa da pesquisa nos anos de 2018 e 2019 (quando se considerou a regional de saúde de Mafra unificada).

Nos estudos e o acompanhamento aos processos em andamento no território, foco desta reflexão, identifica-se quatro redes em implementação e/ou implantada:

1) Rede de Urgência e Emergência (EU): de abrangência macrorregional, envolvia 26 municípios, 13 deles localizados no microterritório catarinense denominado Planalto Norte Catarinenses. Esta rede possui uma central de regulação de leitos em funcionamento por meio do Sistema Nacional de Regulação (SISREG) com o mapeamento de todos os pontos de atenção às urgências e em Serviço de Atendimento Móvel (SAMU).

2) Rede Cegonha $(R C)$ : mesmo que esta rede seja oriunda de programa federal, ela estava sendo implementada no microterritório do Planalto Norte Catarinense. Nos municípios envolvidos são realizados os testes rápidos para as gestantes preconizados pela portaria da RC.

3) Rede da Pessoa Portadora de Deficiência: as discussões em torno dessa rede acontecem em setembro de 2014, quando se identifica apenas um ponto de atenção para esta Rede. Na oportunidade é concebido o Grupo Condutor desta rede na região, com o intuito de aprimorar as discussões acerca do tema. A atividade seguinte à discussão de novembro de 2014 , decorre da realização da I Oficina Técnica dos Ostomizados, na qual o tema central levanta os cuidados. Durante a oficina evidencia-se a necessidade de alinhamento conceitual sobre rede em saúde pública e em especial, sobre essa rede, para que todos os participantes do grupo condutor se familiarizassem com esse processo.

4) Rede psicossocial: a composição desta rede inicia-se em 2013. Aa proposta na época acatada pela CIR, subsidia a formação do Grupo condutor para essa rede. Ocorre o cadastramento de leitos para o atendimento de pessoas com distúrbios psiquiátricos no município de Três Barras e Rio Negrinho. Em 2019 é aprovada pela CIB a nova Política Hospitalar do Estado de Santa Catarinense com o objetivo de estabelecer a política hospitalar para este Estado. Essa política visa ampliar o acesso e a qualidade dos serviços ofertados. São mapeados todos os hospitais do estado com suas potencialidades para o aporte de recursos 
classificados de média e alta complexidade. A formalização dessa rede se dá por meio das pactuações na CIR e na CIB, a qual tem por objetivo organizar, deliberar e monitorar os serviços da Rede de Atenção à Saúde da na região.

\section{DISCUSSÕES}

Durante o período indicado (entre 2015 e 2017 e entre 2018 e 2019), vários episódios sustentaram os aspectos acerca do objeto de pesquisa e estudo, que, sob orientação teórica e conceitual das legislações, programas e propostas, estimularam as mobilizações, a promoção de eventos, a realização de conferências na área de saúde, cujos enfoques cercaram o tema delimitado.

As definições de estruturadas, serviços e tecnologias situadas territorialmente consideradas na concepção das RAS, estas serviram de diretriz para o desencadeamento da implementação e implantação de redes.

Em especial no período entre 2018 e 2019, se confirmou a estagnação da implementação de redes de atenção à saúde nesse território.

Em relação a Rede de Urgência e Emergência, foi constituído um Comitê Gestor Macrorregional das Redes de Atenção à Saúde (Nordeste/Planalto Norte), o qual se caracteriza como instância privilegiada de negociação, articulação e sugestão quanto aos aspectos operacionais do SUS no âmbito dessa Macrorregião de Saúde. Esse comitê subsidia as decisões da Comissão Intergestores Regional $(\mathrm{CIR})$, respeitadas as definições da Comissão Intergestores Bipartite (CIB), constituindo-se como espaço permanente de pactuação e co-gestão solidária e cooperativa no âmbito regional, a partir da identificação, definição de prioridades e de pactuação de soluções para a organização da Rede de Atenção à Saúde. Para além das decisões, realiza o monitoramento dos prestadores de serviços no cumprimento de suas obrigatoriedades.

$\mathrm{Na}$ implementação da Rede Cegonha, a discussão no processo dessa rede circula em torno da referência de gestação de alto risco. No PNC apesar da Maternidade Catarina Kuss estar mapeada como referência, não possui condições operacionais de oferecer o serviço à região. Destaca-se que até o final da etapa da pesquisa, 2019, nos municípios haviam relatos das dificuldades no encaminhamento de suas gestantes de alto risco para uma referência pré-definida, restando para essas gestantes a vagas disponíveis no sistema da Central de regulação de leitos, em todo o território do estado.

Após cinco anos da implementação da Rede da Pessoa Portadora de Deficiência, poucos avanços ocorreram. O grupo condutor dissipou-se e o município de Três Barras que havia demonstrado interesse em sediar um Centro de Especialidades em Reabilitação declinou dessa decisão devido o subfinanciamento do Ministério da Saúde. Esse encaminhamento do MS sobrecarregaria os recursos municipais, uma vez que o município teria que arcar com o restante das despesas 
para manutenção do serviço para a região. Na esfera estadual, as discussões a respeito do tema restringem-se à rede de alta complexidade: Rede de Urgência e Emergência.

Referente a Rede Psicossocial, para a região do Planalto Norte destaca-se a possibilidade de credenciamento de leitos para o atendimento de pessoas com distúrbios psiquiátricos, reforçando desta forma a efetivação da Rede Psicossocial. Além da rede psicossocial, a nova Política Hospitalar do estado de Santa Catarina redefine e amplia os serviços hospitalares que compõem a rede de atenção materno infantil e de urgência e emergência.

As observações sistemáticas sobre o processo de implementação e implantação de redes de atenção à saúde no microterritório catarinense enunciaram, a priori, defasagens na sua constituição, diante do que se preconiza para um SUS eficaz. A concepção de rede em saúde pública e das redes de atenção vem sendo estimuladas como tendência sem retrocesso, na qual é condição "sine qua non" a valorização dos recursos tecnológicos, institucionais e a interação das competências dos trabalhadores da saúde. Mais complexo e conflituoso que se possa evidenciar, no cenário da implementação das redes de atenção primária, há "déficits" acumulados da restrita abrangência das estratégias de saúde da família em operacionalização, quando se analisa a demanda para a saúde pública. Logo, a atenção primária e a prevenção podem ficar comprometidas.

No estado de Santa Catarina, os profissionais que atuam na saúde, integrantes da Comissão Integração Ensino Serviço (CIES) do PNC, que representam instituições de ensino e trabalhadores da saúde, revelam que a atenção básica, promoção da saúde e a educação permanente, seria competência da institucionalidade dessa comissão, (legitimada pelo MS/SGETS, 1996/2007) e dos Núcleos Municipais de Educação Permanente em Saúde (NMEPS) e que na identificação das demandas e necessidades de reforço nesse processo das redes, poderiam contribuir com a proposta de reorientação e educação permanente promovida pela IES local de abrangência no microterritório estudado.

No entremeio desse processo, essas demandas dizem respeito a fatores como resistências e rejeições ao processo das redes; morosidades; visão e versão sobre saúde pública direito de todos divergente do pressuposto constitucional. Além destas questões, há outros elementos relevantes que recaem sobre a baixa autoestima dos trabalhadores da saúde, alta interferência da política partidária na gestão pública da saúde local-regional; controle social inoperante e versão superficial sobre as transformações necessárias na operacionalidade da saúde pública, que interferem em quadros de morbi-mortalidade.

Nos potenciais avanços que o processo poderia ter promovido desde 2007, afirma-se que Rede de Atenção à Saúde na regional de Mafra é frágil. Apesar do conjunto dos municípios ter implantado seus Núcleos Municipais de Educação Permanente em Saúde e estar arregimentando esforços no fortalecimento da atenção primária em saúde, responsabilidade da gestão municipal, vários aspectos dificultam a sua implementação e implantação. Mesmo com as mudanças de pressupostos, o papel dos gestores nesse processo seria de viabilização da 
instituição da política de educação permanente suprimindo-se a individualidade dos municípios em prol da regionalização. Confia-se que é a educação permanente em saúde que poderá contribuir com as reflexões e compreensões necessárias dos fundamentos das políticas públicas e seus desdobramentos.

\section{CONSIDERAÇÕES FINAIS}

Os processos não se movem sem os movimentos do capital humano no seu meio. Por isso uma questão relevante refere-se à adesão do gestor público e sua equipe. Eles precisam assumir a rede de atenção à saúde como estratégia da política pública.

O Estado deve ser o coordenador desse processo, porém, na regional de saúde de Mafra os desencontros, as mudanças de gestão e de gestores vêm atrasando o processo. A falta de empenho na disseminação do conhecimento como compromisso moral do trabalhador da saúde pública se perde pela incompreensão desta sua atribuição e o acúmulo de experiências que subsidiaram a caminhada na implantação da saúde pública, na implementação das redes de atenção, que se perdem com essas mudanças.

Tomado por base esse contexto problematizado, identifica-se que nesse processo, os trabalhadores da saúde ao serem envolvidos no processo, devem envolver-se e se desenvolver-se, pois os desafios na saúde pública e sua operacionalização não cessam. Os estudos e as pesquisas revelam que as superações de cenários e dilemas, em cada fase da organização social desse território, tornam-se evidentes e paradoxais, conforme diagnosticado pelos autores Bazzanella, Gumbowsky, Milani (2016, p. 23-24), que a tramitação dos documentos, setores e entes institucionais embarram em posição política dos sujeitos, pela concepção equivocada sobre a composição e atribuições das políticas públicas como estratégias para o desenvolvimento, o que de fato deve produzir bem estar. Corrobora nessa direção, a falta de intersetorialidade na execução das políticas públicas e de um controle social aguçado e atuando como espaço de exercício da democracia. A constatação mais preocupante, já identificada pelos autores acima, confirmou-se a descontinuidade das ações, programas e intervenções com as alterações das gestões do governo, o que implicou na suspensão de uma acalorada mobilização em favor das redes, para concretização da regionalização da saúde pública.

São os enfrentamentos prováveis que a concepção e implementação das redes de atenção à saúde teriam que enfrentar até consolidarem-se. Em se retardando esse processo o custo social da saúde pública se eleva ao patamar de ineficácia colocando em risco um sistema concebido democraticamente pela população excluída do seu direito à saúde pública. 


\section{AGRADECIMENTOS}

Fomentos da pesquisa finalizada em 2017, recebidos pelo CNPq - Edital Universal 2014

\section{REFERÊNCIAS}

1 Brasil. Constituição da República Federativa do Brasil. Legislação Republicana Brasileira. Brasília, 1988. [acesso em 10 jun. 2019] .Disponível em: <http://www.planalto.gov.br/ccivil_03/constituicao/constitui\%C3\%A7ao.htm>

2 Brasil. Lei $n^{\circ} 8.080$ de 1990 Dispõe sobre as condições para a promoção, proteção e recuperação da saúde, a organização e o funcionamento dos serviços correspondentes e dá outras providências. In. Congresso Nacional. Legislação Republicana Brasileira. Brasília, 1990a. [acesso em 01 jul. 2019]. Disponível em: $<$ http://www.planalto.gov.br/ccivil/LEIS/L8080.htm>

3 Arouca S. Entrevista: Sergio Arouca. Trabalho, Educação e Saúde. sept 2003; 1(2) [acesso em 02 nov 2019]. Doi: http://dx.doi.org/10.1590/S198177462003000200010

4 Mendes E V. As redes de atenção à saúde. Brasília: Organização Pan-Americana da Saúde; 2011.

5 Thiollent M. Notas para o debate sobre pesquisa-ação. In Brandão CR (Org.). Repensando a pesquisa participante (pp. 82-103). São Paulo: Brasiliense, 1999.

6 Minayo MCS. Pesquisa Social: teoria, método e criatividade. Petrópolis: Vozes; 2009

7 Gil AC. Método e técnica de pesquisa social. 4 ed. São Paulo: Atlas; 2002.

8 Milani M L, Vandresen F. O programa nacional de segurança do paciente e as implicações nos serviços de saúde como aspecto relevante ao desenvolvimento regional. DRd - Desenvolvimento Regional em debate. 2019; 9: 478-505. [acesso em 02 nov. 2019]. Doi: https://doi.org/10.24302/drd.v9i0.2089

9 Brasil. Secretaria de Atenção à Saúde. Implantação das Redes de Atenção à Saúde e outras estratégias da SAS. Brasília: Ministério da Saúde; 2014.

10 Santos L. Região de saúde e suas redes de atenção: modelo organizativo-sistêmico do SUS. Ciênc. saúde colet. Abr 2017; 22(4). [acesso em 10 dez 2019]. Doi: https://doi.org/10.1590/1413-81232017224.26392016

11 Brasil. Ministério da Saúde. Portaria n 4.279, de 30 de dezembro de 2010. [acesso em 30 out 2019]. Disponível em: http://bvsms.saude.gov.br /bvs/saudelegis/gm/2010/prt4279_30_12_2010.html 
12 Brasil. Conselho Nacional de Secretários de Saúde. A Atenção Primária e as Redes de Atenção à Saúde/Conselho Nacional de Secretários de Saúde. Brasília: CONASS; 2015.

13 Brasil. Ministério da Saúde. Portaria GM/MS n 95, de 26 de janeiro de 2001. [acesso em 30 jul. 2018]. Disponível em:

http://bvsms.saude.gov.br/bvs/saudelegis/gm/2001/prt0095 2601 2001.html

14 Brasil. Ministério da Saúde. Portaria n².669, de 3 de novembro de 2009. [acesso em 30 out 2019]. Disponível em: http://bvsms.saude.gov.br/bvs/saudelegis/gm/2009/prt2669_03_11_2009.html

15 Brasil. Ministério da Saúde. Portaria MS/GM 687 (30 de março de 2006). Política Nacional de Promoção da Saúde. [acesso em 30 out 2019]. Disponível em: http://bvsms.saude.gov.br/bvs/saudelegis/gm/2010/prtmsgm687

16 Oliveira NRC. Redes de Atenção à Saúde: a atenção à saúde organizada em redes. UNA SUS, UFMA). UDUUFMA: São Luiz; 2016 [acesso em 10 dez 2019]. Disponível em: https://www.unasus.ufma.br/wpcontent/uploads/2019/12/isbn_redes01.pdf

17 Brasil. Decreto $n^{\circ} 7.508$, de 28 de junho de 2011. Regulamenta a Lei no 8.080, de 19 de setembro de 1990. In. Congresso Nacional. Legislação Republicana Brasileira. Brasília; 2011. [acesso em 01 nov 2019]. Disponível em: http://http://www.planalto.gov.br/ccivil_03/_Ato20112014/2011/Decreto/D7508.html

18 Brasil. Ministério da Saúde. Secretaria de Gestão Estratégica e Participativa. A construção do SUS: histórias da Reforma Sanitária e do Processo Participativo. Brasília: Ministério da Saúde; 2006.

19 Brasil. Ministério da Saúde. Plano Nacional de Saúde - PNS: 2012-2015. Brasília, 2011. [acesso 30 out 2019]. Disponível em: http://bvs.saude.gov.br/bvs/publicacoes/plano_nacional_saude_2012_2015.pdf

20 Brasil. Ministério da Saúde. Plano Nacional de Saúde - PNS: 2016-2019. Brasília, 2015. [acesso em 30 out 2019]. Disponível em: https://www.saude.gov.br/images/pdf/2019/dezembro/02/Plano-Nacional-deSaude---PNS--2016-2019-.pdf

21 Bazzanella SL, Gumbowsky A, Milani ML. Memorial 10 anos do Programa de Mestrado em Desenvolvimento Regional da Universidade do Contestado. DRd Desenvolvimento Regional em debate. Jul 2016; 6(2, ed. esp): 5-25. [acesso em 01 nov 2019]. Disponível em: file:///C:/Users/Maria\%20Luiza/Downloads/1231Texto\%20do\%20artigo-4811-2-10-20160722.pdf

Artigo recebido em: 06/02/2020

Artigo aprovado em: 20/03/2021

Artigo publicado em: 26/03/2021 